\title{
Pemerolehan Kosakata Dalam Bahasa Jepang Melalui Pengajaran Bunpoo dan Kaiwa
}

\author{
Made Ratna Dian Aryani \\ Universitas Udayana \\ dian_aryani@unud.ac.id
}

\begin{abstract}
The focus of this article is vocabulary acquisition of Japanese through demonstrative methods. This article is the result of research on the methods of vocabulary acquisition of Nursing Science students of Faculty of Medicine, Universitas Udayana. This article aims to explain the use of language teaching methods and strategies in non-language classes. The method used in this research is descriptive qualitative method. This article refers to the concept and theories formulated by Bandura (1986). Natural methods are used in learning Japanese grammar. Vocabulary acquisition can be obtained through the explanation of simple vocabularies that is started from a classroom environment, or through the dictionary used in the study. While, in conversation learning, the methods used are shadowing method and conversation method, which is supported by demonstrative strategies and the "question and answer" strategy. The strategy is employed by providing similar questions to all of the learners that make them try to look for different vocabularies to answer the question. The demonstrative strategy is used for observation, imitation and repetition, as well as development of the material of the context in real life situations.
\end{abstract}

Key words: vocabulary acquisition, demonstrative method, natural method, conversation method

\section{Intisari}

Penelitian ini difokuskan pada pemerolehan kosakata bahasa Jepang menggunakan metode demonstratif. Artikel ini merupakan hasil penelitian dari pengajaran yang diberikan untuk mahasiswa Program Studi Ilmu Keperawatan, Fakultas Kedokteran Universitas Udayana. Tujuan penelitian ini adalah menjelaskan penggunaan metode dan strategi pengajaran bahasa pada kelas nonbahasa. Metode yang digunakan dalam penelitian ini adalah metode deskriptif kualitatif. Penelitian ini menggunakan teori dan pendapat dari Bandura (1986). Pembelajaran tatabahasa pada bahasa Jepang menggunakan metode natural/alami. Kosakata diperoleh melalui penjelasan yang sederhana pada saat proses belajar mengajar tersebut. Hal itu dimulai dengan kosakata yang didapat di dalam kelas atau penggunaan kamus saat pembelajaran. Pada pengajaran kaiwa, metode shadowing dan percakapan diaplikasikan bersama dengan strategi demonstratif dan strategi "bertanya dan menjawab". Metode tersebut dipergunakan untuk semua pembelajar, sehingga para pembelajar berusaha untuk menjawab dengan mencari kosakata yang berbeda. Sedangkan strategi demonstratif dipergunakan observasi dan peniruan atau pengulangan kosakata sebagai pengembangan dalam pembelajaran bahasa Jepang sesuai dengan konteks dan situasi

Kata kunci: pemeroleh kosakata, metode demonstratif, metode natural, metode percakapan 


\section{Pendahuluan}

Pendidikan pada dasarnya berupaya dan bertujuan untuk terlaksananya proses transfer ilmu pengetahuan beserta informasi dalam segala hal. Dunia pendidikan juga melaksanakan berbagai cara, agar proses-proses tersebut di atas terjadi secara optimal dan efisien. Namun demikian, dunia pendidikan masih menghadapi beragam kendala serta kendala dalam pencapaian tujuan yang diharapkan.

Terkait dengan tugas pengajar untuk mentransfer ilmu, terdapat pula kewajiban untuk memberikan motivasi dan memberikan pendidikan karakter kepada para pembelajar. Dengan kurikulum yang ada sekarang yang berbasis student learning center, selain memberi kebebasan kepada para pembelajar dalam proses belajar dengan mencari sumber belajar melalui media pembelajaran, pengajar selalu memberi arahan untuk menjadi pendengar yang baik, memperlakukan pembelajar dengan baik, sehingga proses belajar mengajar dapat terwujud dengan baik dan saling melengkapi di kelas.
Di Progran Studi Ilmu Keperawatan, Fakultas Kedokteran Universitas Udayana sejak beberapa tahun yang lalu telah diselenggarakan mata kuliah bahasa Jepang. Hal tersebut terkait dengan kerjasama yang terjalin antar universitas, yaitu Universitas Udayana dengan universitas yang ada di Jepang. Selain itu, melihat banyaknya permintaan lowongan pekerjaan di Jepang yang berkaitan dengan kesehatan, khususnya keperawatan. Pengajaran bahasa Jepang untuk mereka yang tidak mengambil jurusan bahasa Jepang disebut dengan Pengajaran Japanese for Special Purpose (selanjutnya akan disingkat dengan JSP). Pengajaran JSP berbeda dengan pengajaran mata kuliah lain. Dalam pengajaran JSP, pengajar dituntut untuk memberikan motivasi kepada para pembelajar. Pembelajaran JSP tidak sekedar berupa proses belajar mengajar akademis seperti tata bahasa, percakapan dan menulis huruf Jepang sesuai dengan topik atau silabus saja. Dalam JSP terdapat harapan dan tuntutan sebagai pengajar yaitu dapat menumbuhkan keberanian dalam diri pembelajar untuk 
berbicara agar pembelajar berani berkomunikasi secara sederhana dan percaya diri dalam berbicara menggunakan bahasa Jepang. Terdapat pula harapan untuk meningkatkan pemerolehan kosakata dalam bidang ilmu yang ditekuni oleh pembelajar baik itu bahasa Jepang, dan bahasa asing lainnya. Selain itu, pengajaran JSP ini tidak hanya pengajaran tata bahasa, percakapan atau menulis huruf saja, tetapi diajarkan pula kebudayaan Jepang seperti CCU (Cross Culture Understanding). Pengajaran ini sangatlah diperlukan mengingat bahasa Jepang memiliki ciri khas dalam tingkatan kesantunan berbahasa. Dan sangat lekat budaya Jepang dalam kehidupan sehari-harinya.

\section{Metodologi Penelitian}

Metode yang digunakan dalam penelitian ini adalah metode kesemestaan kognitif yang menyatakan bahwasanya bahasa diperoleh berdasarkan struktur-struktur kognitif deriamotor. Struktur ini diperoleh melalui interaksi dengan benda-benda atau di sekitarnya. Pemerolehan Bahasa bergantung pada pemerolehan proses- proses kognitif lalu memperoleh lambang-lambang linguistik (Piaget, 1995, h. 241).

\section{Hasil dan Pembahasan}

Pengajaran JSP untuk program studi Keperawatan di Universitas Udayana diberikan kepada mahasiswa semester II di setiap tahunnya. Dengan berlakunya sistem blocking bagi mahasiswa di Fakultas Kedokteran, proses pengajaran JSP ini disusun sedemikian rupa agar dalam terselenggara dengan baik dan lancar. Sistem blocking adalah sistem kurikulum yang digunakan pada Fakultas Kedokteran Univesitas Udayana bedasarkan mata kuliah yang terintegrasi dan terpadu dalam setiap semesternya.

Pemerolehan bahasa menurut Krashen (2003, h.194) adalah proses pemahaman dan penghasilan bahasa pada manusia melalui beberapa tahap, mulai dari meraban sampai kefasihan penuh. Proses pembelajaran ini berangkat dari penekanannya terhadap makna proses internal, mental manusia. Bandura (1986, h.58) menyatakan bahwa belajar adalah sebuah proses 
mental, dan bukan behavioral, hingga terjadi proses transformasi pengetahuan dari seseorang kepada orang lain.

Proses belajar mengajar JSP untuk pembelajar non kebahasaan, tentunya modal utama yang diperlukan adalah keberanian dan kepercayaan diri untuk berbicara salah. Begitu juga dalam pengajaran mata kuliah Bahasa Jepang di Prodi Ilmu Keperawatan Fakultas Kedokteran Universitas Udayana, ketika mengajak pembelajar untuk berbicara, mungkin pembelajar hanya diam, tersenyum atau tertawa. Kondisi ini mungkin saja terjadi, karena tidak semua pembelajar di Prodi Keperawatan memiliki dasar-dasar kemampuan berbahasa Jepang. Pembelajar yang telah memiliki kemampuan berbahasa Jepang, dikarenakan di Sekolah Menengah Umum, telah diajarkan untuk beberapa semester. Bagi pembelajar yang belum pernah belajar samasekali, hal tersebut memang akan terjadi, dan tentunya situasi tersebut tidak boleh berlarut dan harus segera diubah. Proses pembelajaran dengan strategi "tanya-jawab" harus sering dilakukan, dan "paksa" pembelajar untuk berbicara. Memberikan pujian merupakan hal yang dapat memunculkan keberanian dan kepercayaan diri dari para pembelajar itu sendiri.
Proses belajar mengajar di Ilmu Keperawatan (PSIK) Universitas Udayana biasanya disesuaikan dengan jadwal yang telah diberikan yaitu dengan kurikulum blocking system, maka proses belajar mengajar pun akan terjadi 3-4 minggu secara berturut-turut, selama 8 jam dalam satu hari. Sejalan dengan sistem ini, mata kuliah bahasa Jepang pada JSP pun diberikan dalam waktu yang terbatas. Materi meliputi tata bahasa dasar, percakapan dan menulis/mendengar. Pada umumnya, pembelajaran bahasa Jepang dengan metode ilmiah memiliki urutan pelajaran yakni menyimak (listening), mendengar (hearing), percakapan (speaking), membaca (reading), dilanjutkan dengan menulis (writing), dan gramatika (grammar). Dalam JSP ini pembelajaran bahasa Jepang dasar dan menulis diajarkan menggunakan metode alami (natural method). Metode alami ini bisa disertai dengan metode shadowing. Metode shadowing merupakan metode yang digunakan untuk meningkatkan kompetensi menyimak. Teknik ini dipergunakan untuk menekankan kemampuan pembelajar menirukan suatu narasi, sehingga dapat memahami isi wacana sederhana. Metode ini dapat dilakukan dengan berpasangan, sehingga pembelajar dapat memberikan komentar dan pertanyaan berkaitan dengan narasi 
tersebut secara langsung ke dalam Bahasa Sasaran. Pada JSP di PSIK (Program Studi Ilmu Keperawatan) Universitas Udayana ini, perkuliahan Bahasa Jepang dilaksanakan dalam "kelas besar". Kelas besar yang dimaksudkan di sini adalah dalam satu kelas dengan jumlah pembelajar yang banyak (kira-kira 65-70 mahasiswa) dalam satu kelasnya. Proses belajar mengajar tatabahasa dan menulis huruf didahulukan dalam pengajarannya dimaksudkan agar bagi pembelajar pertama kali belajar bahasa Jepang dapat mengetahui dan mendapatkan pengetahuan kosakata dasar dan pola-pola pembentukan kalimat dasar bahasa Jepang. Selanjutnya, pembelajar tidak menjadi bingung dan pemerolehan kosakata dalam membentuk kalimat sederhana pun dapat berjalan dengan baik dan lancar. Mengingat waktu pembelajaran bahasa Jepang ini yang sangat singkat, maka sebelum mulai masuk dalam pengajaran percakapan, proses belajar mengajar tatabahasa bahasa Jepang telah dimulai terlebih dahulu sebanyak 2 kali pertemuan.

\section{Bandura (1986) menyatakan}

bahwa penyebutan metode alami (natural method) karena dalam proses pembelajaran, pembelajar dibawa ke alam seperti halnya pembelajaran bahasa ibu. Pembelajaran diawali dengan memperkenalkan kata-kata yang sederhana yang telah diketahui oleh para pembelajar. Tahap berikutnya adalah memperkenalkan kosakata benda-benda dalam bahasa Jepang mulai dari benda-benda yang ada di dalam kelas, di rumah dan luar kelas. Untuk hal ini sangat diperlukan alat peraga dan kamus yang dapat digunakan sewaktu-waktu. Alat peraga ini digunakan pada saat menjelaskan dan mengartikan kata-kata sulit dalam bahasa asing, dan metode ini berguna untuk memperkaya kosakata sebagai syarat utama menguasai bahasa asing.

Pada materi Bunpoo (tata bahasa), pengajaran kosakata menggunakan kartu bergambar. Penggunaan kartukartu tersebut memudahkan pembelajar untuk menghafalkan kosakata. Selanjutnya, pembelajar diajak untuk membuat kelompok/ berpasangan agar pembelajaran semakin menarik dan dapat saling mengingatkan dalam kelompok masing-masing. Selain itu, mahasiswa diwajibkan menghafalkan minimal 10 kosakata dalam satu hari. Hari berikutnya, kosakata yang telah dihafalkan tersebut, dapat dipraktekkan dengan membuat 
percakapan dengan pola-pola kalimat

sederhana bahasa Jepang Jepang yang

telah diajarkan sebelumnya.

Selanjutnya, dalam pembelajaran

Bunpoo, mahasiswa diperkenalkan

pada sistem kebermarkahan dalam

bahasa Jepang. Struktur kalimat bahasa Jepang mengandung partikel (wa, ga, ni, he, o/wo, de, kara, made) yang menunjukkan hubungan gramatikal dalam kalimat. Partikel merupakan sebagai bagian dalam kalimat yang menyatakan fungsi gramatikal konstituen yang dimarkahinya (Chino, 1991, h.vii). Partikel ini tidak bisa berdiri sendiri sebagai kata. Kaidah bahasa Jepang menyatakan bahwa partikel sesungguhnya tidak mempunyai makna leksikal, kecuali makna yang berhubungan dengan konteksnya, yakni makna gramatikal. Ini menjadi dasar utama pembelajaran Bunpoo. Setelah mahasiswa memahami dasar Bunpoo ini, pembelajaran dilanjutkan dengan memperkenalkan siswa pada pola kalimat sederhana bahasa Jepang. Contoh-contoh kalimat sederhana yang diajarkan kepada mahasiswa antara lain:

1. Pola kalimat sederhana: $\sim$ wa $\sim \operatorname{desu} .(+)$

$\sim$ wa desu ka. (?)

$\sim$ wa dewa arimasen $(-)$

2. Kata Penunjuk benda.

- Kore, sore, are

<ini, itu>

- Kono, sono, ano

$<$ ini, itu>

- Dore?,Dono?

<yang mana>

3. Kata penunjuk tempat.

- Koko, soko, asoko

$<$ di sini, di situ, di sana $>$

- Kochira, Sochira, achira $<$ di sini, di situ, di sana $>$

- Doko?, Dochira?

$<$ di mana $>$

4. Angka, waktu, hari, tanggal, bulan, tahun

- Ichi, ni, san ...

$$
<1,2,3 \ldots\rangle
$$

- Jikan

$<$ waktu>

- Youbi

$<$ hari>

- Tsuitachi, futsuka, mikka ...

$<\operatorname{Tg} \mid$ 1. Tgl $2, \operatorname{tg} \mid 3 \ldots>$

- Ichigatsu, nigatsu, sangatsu, shigatsu .... 
<Januari, Februari, Maret, April, ...>

- 2018 nen

(nisen juu hachi nen )

$<$ Tahun 2018>

Contoh-contoh di atas (1-4) merupakan materi Bunpoo yang diajarkan kepada mahasiswa PSIK. Materi-materi tersebut meliputi; (1) pola kalimat sederhana yang wajib mahasiswa ketahui agar memudahkan mahasiswa menyusun kalimat sendiri. Baik dalam pola kalimat bentuk positif $(+)$, pola kalimat bentuk negatif (-), dan pola kalimat bentuk interogatif (?); (2) merupakan pola kalimat bentuk penunjuk benda, yang mana menunjukkan perbedaan penggunaan kore, sore are dengan kono, sono, ano. Bahwa kore, sore, are bisa berdiri sendiri, sedangkan kono, sono, ano tidak dapat berdiri sendiri. Artinya kono, sono, ano haruslah digabungkan terlebih dahulu dengan kata benda. Kono + KB (Kata Benda), sono + KB, dan ano + KB. Kata tanya yang digunakan untuk kata penunjuk tersebut adalah dore dan dono, kedua katapen ini penggunaannya sama dengan kata penunjuknya; (3) kata penunjuk tempat koko, soko, asoko dan kochira, sochira, achira merupakan kata penunjuk tempat yang sama-sama bisa berdiri sendiri. Perhatikan contoh di bawah ini:

5. Koko wa kaigishitsu desu. $<$ Di sini adalah ruang rapat $>$

6. Koko wa Budi san desu. (x) $<$ Di sini/ ini adalah Tuan Budi>

7. Kochira wa kaigishitsu desu. $<$ Di sini adalah ruang rapat $>$

8. Kochira wa Budi san desu. $<$ Di sini/ ini adalah Tuan Budi>

Penggunaan koko <di sini> pada kalimat contoh (6) di atas, secara gramatikal Bahasa Jepang adalah benar, namun menjadi tidak santun dan tidak berterima dalam Bahasa Jepang bila dipergunakan untuk menunjuk benda hidup (orang). Perbedaannya adalah penggunaan kochira, sochira, achira dianggap lebih sopan dibandingkan koko, soko, asoko. Kochira, sochira, dan achira pun dapat digunakan sebagai penunjuk orang; (4) materi mengenai angka yang berkaitan dengan waktu (jam), tanggal, bulan, tahun.

Walaupun dengan waktu yang cukup singkat, dalam program JSP di PSIK diajarkan pula kata sifat/ adjektif (keiyoushi 'i' dan 'na') serta 
perubahannya dalam bentuk kala, kata kerja/ verba (dooshi) serta perubahannya dalam bentuk kala pula, dan pola-pola kalimat lain (modalitas) yang sederhana. Pada kelas Bunpoo (tatabahasa Jepang) ini walaupun dengan kelas besar, latihan tetap harus dilakukan, baik dengan lisan maupun tulisan.

Selain mengajarkan tentang tatabahasa bahasa Jepang, secara nonlinguistik pun yaitu budaya Jepang pun dijelaskan budaya Jepang. Misalnya, saat berkenalan dengan orang Jepang kita harus melakukan ojigi. Ojigi adalah membungkukkan badan sebagai tanda hormat kepada lawan bicara. Ojigi tersebut dibarengi dengan mengucapkan Douzo yoroshiku onegaiitashimasu. Setiap kali memperkenalkan diri dengan Bahasa Jepang, maka kalimat Douzo yoroshiku onegaiitashimasu yang bermakna '(saya) senang berkenalan/ berjumpa/ bertemu dengan anda'. Tidak semua percakapan Bahasa Jepang yang menggunakan kalimat douzo yoroshiku atau yoroshiku onegaiitashimasu itu akan bermakna sama. Ungkapan yoroshiku onegaiitashimasu memiliki arti yang berbeda-beda berdasarkan situasi dan kondisi. Ungkapan ini dalam konteks perkenalan atau memperkenalkan diri seperti di atas, maka akan bermakna <senang berkenalan dengan anda> Pengucapan ungkapan tersebut dimaksudkan bahwa ucapan tanggapan atau respon kepada lawan bicara karena merasa senang berkenalan dengan lawan bicara. Pada dasarnya kalimat yoroshiku onegaiitashimasu dapat bermakna (1) salam kenal, (2) tolong ya, (3) saya mohon bimbingan/dorongan, tolong bantu saya, (5) mohon kerja samanya, (6) tolong ajari/ bombing saya, (7) jaga (rumah) baik-baik. Makna tersebut disesuaikan dengan konteks kalimatnya secara keseluruhan.

Pengajaran budaya Jepang ini bertujuan memberikan pemahaman tentang budaya Jepang yang sangat berbeda dengan budaya barat yang 'to the point' dalam menyampaikan sesuatu.

Pembelajaran selanjutnya adalah proses pembelajaran kaiwa (percakapan). Dalam kaiwa (percakapan) tersebut, akan dibagi dalam kelompok-kelompok kecil (small 
grup discussion/ SGD). Dalam satu kelompok-kelompok kecil tersebut terdiri dari 10-12 pembelajar/mahasiswa. Pembelajaran kaiwa (percakapan) ini, setiap pembelajar/ mahasiswa diwajibkan untuk berbicara dan akan dituntun untuk melakukan percakapan dengan memberikan contoh-contoh. Untuk setingkat shokyuu (level dasar), pengajar menanyakan:

9. A: しつれいですが、お名前は? Shitsurei desuga, Onamae wa? <Maaf, namanya siapa?>

B: Lee です。

(1) Lidesu. $<$ Lee >

A: Rii さんですか。

(2) Rii san desu ka? <Tuan/ Nyonya Rii kah?>

B:いいえ、Lee です。 lie, (1) Lidesu.

< Bukan, saya Lee>

10. A: 明日 Singaraja へ行きます。 Ashita (1) Singaraja e ikimasu. <Besok akan pergi ke Singaraja $>$

B: なにで行きますか。 Nani de ikimasuka? < Pergi naik apa?>

A: バスで行きます。

(3) Basu de ikimasu. $<$ Naik bis>

B:一人で行きますか。
Hitori de ikimasuka?

<Pergi sendiriankah?>

A:いいえ、会社の人と行きます。 lie, kaisha no hito to ikimasu. <Tidak, pergi dengan teman kantor.>

11. A: お元気ですか。 Ogenki desuka? <Apa kabar? / Sehatkah?>

B: はい、元気です。 Hai, genki desu.

< Ya, baik/ sehat.>

A: お仕事はどうですか。

(1) Oshigoto wa doo desuka? $<$ Pekerjaan(mu/anda) bagaimana?>

B: そうですね。忙しいですが、 面白いです。

Sou desu ne. (2) Isogashii desu ga, omoshiroi desu. $<$ Ya, sibuk tetapi (pekerjaan saya) menarik.>

12. A: さあ、会議を始めましょう。 Saa, kaigi o hajimemashou. <mari (kita) mulai rapatnya.>

あれ?Miraa さんは?

Are? Miraa san wa?

< Ehh? Tuan Miller (di mana)?>

B: 今 電話をか/ています。 Ima denwa o kakete imasu. $<$ Sekarang sedang bertelepon.>

A：そうですか。じや、ちょっと ま ちましょう。 Sou desuka? Ja, chotto machimashou.

Jurnal Lingua Applicata Volume 2 Nomor 1 September 2018 
$<$ Oh begitukah? Baik, mari kita tunggu sebentar.>

Model percakapan yang digunakan dalam pembelajaran JSP misalnya seperti contoh percakapan 5 8. Pada prosesnya, mahasiswa diminta saling berpasangan untuk melakukan percakapan tersebut, dengan mengganti kosakata yang digarisbawahi dengan kosakata yang sesuai.

Pada contoh percakapan (5), mahasiswa diharapkan mencari kosakata nama -nama diri (nama-nama orang) yang mirip. Percakapan tersebut bertujuan pembelajar bisa melakukan komunikasi sederhana untuk menanyakan nama. Kemiripan tersebut, dimaksudkan saat pembelajaran berkenalan dengan orang asing untuk pertama kalinya, ada kemungkinan kita salah dengar dari nama yang diucapkan. Pada contoh percakapan (6), mahasiswa bercakapcakap untuk pergi ke suatu tempat. Mahasiswa diharapkan mengganti kosakata nama tempat-tempat yang berbeda dan kosakata alat transportasi yang berbeda-beda pula.

Pada contoh percakapan (7), percakapan tersebut mahasiswa diharapkan mencari kosakata mengenai kata sifat yang menunjukkan kata sifat yang bertentangan satu dengan yang lainnya. Pada contoh percakapan (8), mahasiswa diharapkan mengubah kata kerja menjadi pola bentuk sedang berlangsung $\{\sim$ te imasu\}. Dengan memberikan pertanyaan yang sama kepada masing-masing pembelajar kaiwa, hal ini akan sangat membantu bagi para pembelajar untuk berusaha berlatih mencari kosakata yang berbeda untuk jawaban pembelajar sendiri. Tentunya, sebelum latihan "tanya jawab" ini berlangsung, pengajar telah membuat "aturan main" yang diterapkan bagi pembelajar untuk tidak diperbolehkan menjawab yang sama dari masing-masing pembelajar. Tujuannya adalah untuk menambah kosakata bagi pembelajar masingmasing.

Selain itu pembelajar pun menciptakan sparing partner (2 mahasiswa) yang diharapkan selanjutnya pembelajar untuk membuat kaiwa baru sendiri secara berpasangan. Dengan topik yang telah ditentukan, pembelajar wajib mengisi rumpang yang kosong dengan kosakata yang 
berbeda setiap pasangan kelompoknya. Selanjutnya pembelajar diwajibkan untuk mempresentasikan hasil dari percakapan yang mereka buat di depan kelas. Hal ini dapat memberikan perhatian bagi pasangan kelompok yang lain untuk belajar kosakata yang berbeda, selain yang pasangan kelompok mereka buat.

Fokus utama dalam pembelajaran kaiwa (percakapan) adalah bukan mengutamakan kebenaran secara gramatikal, namun lebih bertujuan mencari maksud, kelancaran, dan keberanian pembelajar dalam mengungkapkan pendapat serta keberterimaan dalam bahasa yang dipelajari. Karena hal ini terkait dengan pengaruh bahasa ibu yang digunakan oleh para pembelajar bahasa itu sendiri. Hal ini berkaitan dengan bahasa Jepang yang secara gramatikal memiliki susunan pola MD 'Menerangkan Diterangkan' yang berbeda dengan bahasa Indonesia atau bahasa daerah yaitu DM 'Diterangkan Menerangkan'. Dengan belajar dalam kelompok, pembelajar akan lebih berani menyatakan pendapat ketika berada di suatu kelompok, sehingga mereka mampu membuat eksplorasi yang baik ketika bekerja sama.

Strategi yang perlu diajarkan kepada pembelajar kaiwa (percakapan) ketika kemampuan para pembelajar telah meningkat adalah "menyapa orang dengan sopan”, “meminta sesuatu dengan baik", atau "bagaimana cara memulai pembicaraan dengan orang yang belum dikenal”. Strategi percakapan yang baik akan membawa mereka bukan hanya pada sistem bahasa itu sendiri, namun lebih kepada budaya serta nilai moral sebuah bahasa.

Dalam proses belajar mengajar khususnya dalam mata kuliah kaiwa, (percakapan) secara linguistik sering terjadi pelesapan atau pun penambahan kata. Perubahan tersebut harus dijelaskan dengan baik kepada para pembelajar karena hal ini berkaitan dengan kesantunan berbahasa. Bahasa Jepang merupakan bahasa yang mempunyai cara-cara untuk menunjukkan tingkatan kesantunan berbahasa, yakni dengan menggunakan ungkapan atau kalimat untuk meninggikan orang lain dan merendahkan diri sendiri. Pemakaian 
ragam sopan yang menjadi salah satu karakteristik bahasa Jepang adalah untuk mengungkapkan rasa hormat terhadap lawan bicara atau orang yang dibicarakan (Iwasaki, 1999, h.54). Tingkat kesantunan bahasa Jepang ditandai oleh unsur-unsur gramatikal dengan menggunakan perubahan bentuk (grammaticalised politeness) serta pilihan kata (lexicalised politeness).

Proses pembelajaran ini mengacu pada pendapat Bandura (1986) yang menggunakan metode percakapan melalui strategi demonstratif (Demonstrative Strategy). Mengingat para pembelajar tidak mempunyai kemampuan dasar yang sama, maka sesuai dengan inti strategi demonstratif yaitu pemanfaatan observasi dan imitasi (peniruan) dalam proses transfer informasi serta pengetahuan di kelas. Strategi ini untuk mencapai tujuan pendidikan yang efisien, tentunya sangat efektif serta optimal.

Tujuan utama dari penerapan strategi ini adalah mengenalkan keterampilan dan atau pengetahuan baru kepada pembelajar melalui observasi dan imitasi (peniruan).
Strategi ini dapat diaplikasikan di hampir tiap jenis mata pelajaran/ mata kuliah baik itu ilmu sosial, matematika, musik, dan bahasa.

\section{Penerapan Strategi Demonstratif}

Adapun prosedur penerapan dari startegi demonstratif adalah sebagai berikut:

1. Scene Setting. Ini merupakan tahapan pertama yang harus dilaksanakan yaitu pengaturan suasana dan kondisi kelas agar pembelajar dapat melihat, mendengarkan dengan baik saat proses demonstratif berlangsung. Selain itu, hal tersebut juga dapat dijadikan alat untu menarik minat pembelajar.

2. Explaining dan Demonstrating materi. Pada bagian ini, pengajar atau yang mendemonstrasikan strategi ini harus: 1) Terlihat segar dan antusias; 2) menjelaskan dan mendemonstrasikan materi tiap bagian yang diajarkan dengan jelas; 3) Sering memeriksa para 
pembelajar sejauh mana

pemahaman dan keseragaman

pemahaman pembelajar atas

materi yang telah dijelaskannya,

melalui metode feedback dan

key teaching point; dan 4)

Melibatkan para pembelajar

dalam proses belajar mengajar

yang sedang berlangsung.

3. Practising Under Teaching Feedback. Bagian ini, melalui pengawasan para pengajar, para pembelajar diajak untuk mempraktekkan sendiri kemampuan pengetahuan baru tersebut. Pengajar harus menjadi fasilitator, memeriksa, membimbing, dan menemani pembelajar selama proses belajar mengajar tersebut berlangsung. Sehingga bila terjadi kesalahan-kesalahan dalam kelas selama proses belajar mengajar tersebut berlangsung, dapat segera dikoreksi oleh pengajar. Jika perlu dilakukan pengulangan proses explaining dan demonstating seperti sebelumnya.
4. Reviewing. Setelah semua prosedur dilaksanakan, reviewing ini berkaitan dengan situasi real life, hal ini merupakan pengembangan konteks materi atau skill yang telah dipelajari oleh pembelajar sebelumnya dengan skala lebih besar.

Strategi ini digunakan dalam proses belajar mengajar bahasa Jepang di Program Studi Ilmu Keperawatan Fakultas Kedokteran Universitas Udayana. Hasil yang diperoleh sangatlah bagus. Dilihat dari hasil ujian mahasiswa PSIK (Program Studi IImu Keperawatan), rata-rata nilai adalah 8,o. Dari rentang nilai yang ditentukan adalah $71-75=$ cukup, $76-80=$ baik, dan $81-85=$ sangat baik. Antusiasme mahasiswa pun dalam belajar bahasa Jepang terlihat dari raut wajah yang menunjukkan gembira, ceria, senang dari para mahasiswa setiap kali proses belajar mengajar dilaksanakan.

\section{Kesimpulan}

Pengajaran Japanese for Special Purpose (JSP) kepada mahasiswa program studi Ilmu Keperawatan 
tentunya berbeda dengan pengajaran bagi pembelajar bahasa Jepang pada khususnya. Ini disebabkan oleh minat dan kemampuan dasar dari pembelajar yang berbeda-beda. Sehubungan dengan hal tersebut, maka diperlukan metode dan strategi pembelajaran tertentu.

Metode yang dipergunakan dalam pengajaran Japanese for Special Purpose adalah metode alami/natural (Natural Method). Metode ini dipergunakan ketika pembelajar dalam kondisi "kelas besar", misalnya pada saat materi Bunpoo atau tata bahasa bahasa Jepang. Pembelajar pertama-tama diajarkan kosakata sederhana yang telah diketahui pembelajar, mulai dari benda-benda yang ada di dalam kelas, di rumah dan luar kelas. Di kelas disediakan alat peraga dan kamus yang dapat digunakan sewaktu untuk memperbanyak perbendaharaan katakata.

Metode lain yang dipergunakan dalam pembelajaran ini adalah metode shadowing dan metode percakapan (Conversation Method). Dalam metode ini pembelajar bercakap-cakap secara berpasangan atau pun secara langsung diajak berbicara dengan bahasa Jepang secara "tanya jawab”. Strategi ini dipergunakan dengan memberikan pertanyaan yang sama kepada setiap pembelajar, supaya pembelajar berusaha untuk mencari kosakata yang berbeda, sehingga pembelajaran pemerolehan kosakata bagi pembelajar akan efektif dan optimal. Metode shadowing dan metode percakapan ini diharapkan bagi pembelajar untuk membentuk kelompok-kelompok kecil (10-12 mahasiswa). Metode ini didukung pula dengan strategi demonstratif bagi pembelajar dalam pembelajaran kaiwa. Karena tujuan utama dari penerapan strategi ini adalah mengenalkan ketrampilan dan atau pengetahuan baru kepada pembelajar melalui observasi dan peniruan. Dengan metode natural dan demonstatif tersebut, hasil belajar bagi pembelajar bahasa Jepang di kelas Keperawatan ini terbukti bagus. Hal tersebut dapat dilihat dari hasil ujian mahasiswa dengan nilai rata-rata 80 .

\section{Daftar Pustaka}

Bandura, A. (1986). Social Learning Through Imitation. Jones, Marshall R. (Ed), (1962). Nebraska Symposiun on Motivation, 1962., (pp. 211-274). 
Oxford, England: Univer. Nebraska Press, xiii, $330 \mathrm{pp}$.

(2001). Sosial Cognitive Theory: An Agentic Perspective Annual Review of Psychology. Vol. 52: 1-26. California: Stanford University

Benner, D. G. (1985). Encyclopedia of Psychology. Grand Rapids: Baker Book House. h. 98

Boeree, C. (2008). Personality Theories: Melacak Kepribadian Anda Bersama Psikolog Dunia. Yogyakarta: Prismasophie. H. 240

Chino, N. (1996). Partikel Penting Bahasa Jepang. Jakarta: Kesaint Blanc.

Clark, H. H. dan . V. Clark. (1977). Psychology and Language. New York: Harcourt Brace Javanovich, Inc.

Iwasaki, S. (1999). Japanese. Tokyo: John Benyamins Publising Company.

Johnson, M. (2004). A Philosophy of Second Language Acquisition. New Haven, CT: Yale University Press

Krashen, S. (2003). Explorations in Language Acquisition and Use: The
Taipei Lectures. Portmouth, $\mathrm{NH}$ : Heinemann

Long, M. H. (1996). The Role of the Linguistic Enviroment in Second Language Acquisition In Handbook of Second Language Acquisition,ed. W.C. Ritchie and T. K. Bhatia, 413468. New York: Academic Press

Piaget, J. (1995). Sociological Studies. London: Routledge

Tim Penyunting Japan Foundation. (2017). Marugoto Bahasa dan Kebudayaan Jepang: Tingkat Dasar 1 A1: Aktivitas. Jakarta: Kesaint Blanc

Tim Penyunting Japan Foundation. (2017). Marugoto Bahasa dan Kebudayaan Jepang: Tingkat Dasar 1 A1: Pemahaman. Jakarta: Kesaint Blanc

Tim Penyusun Dosen Sastra Jepang Fakultas Ilmu Budaya Universitas Udayana. (2015). Pengajaran Bahasa Jepang Untuk Program Studi Ilmu Keperawatan: Universitas Udayana. 